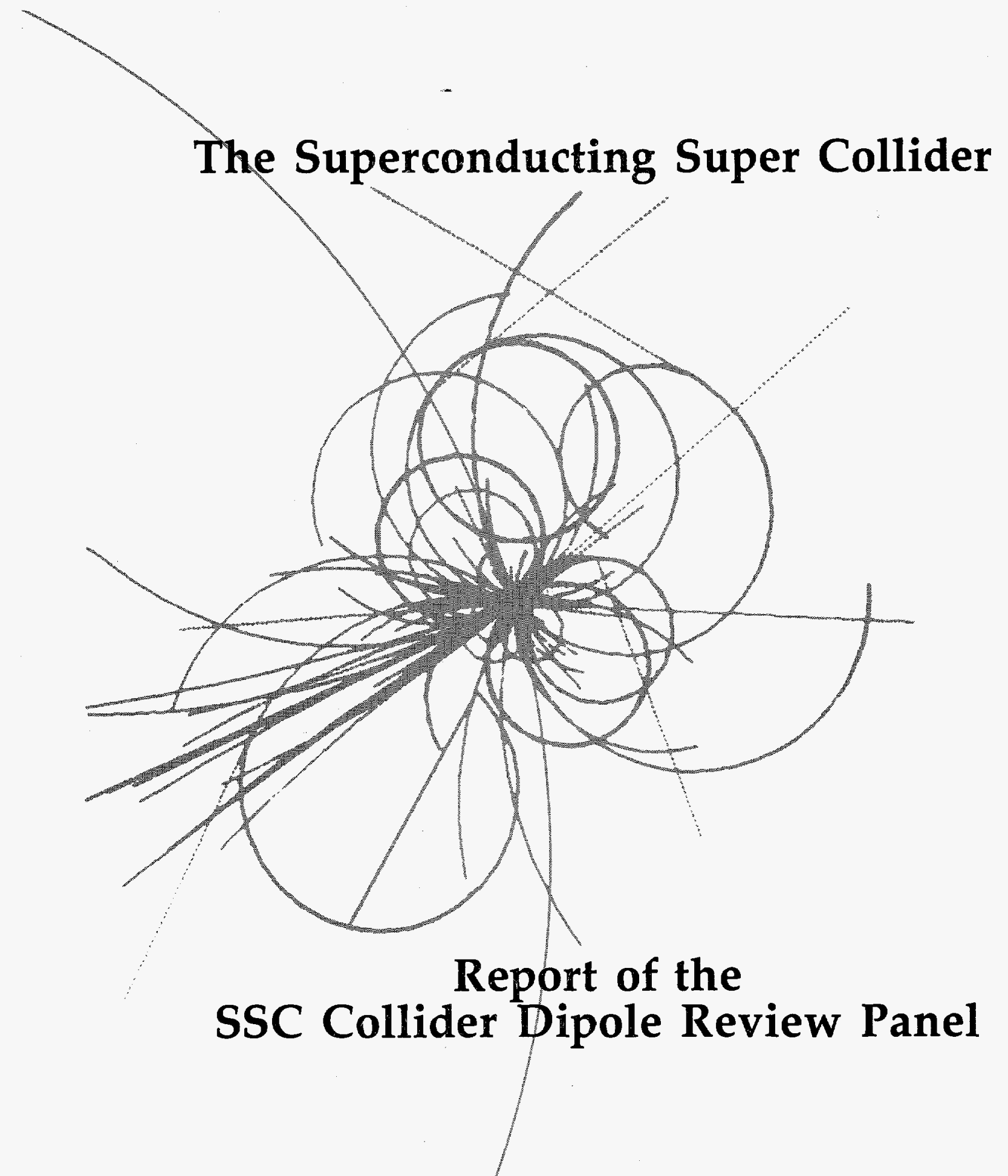

G. Voss, DESY and T. Kirk, SSC/CDG, Editor SSC Central Design Group

June 1989

DISTRIBUTION OF THIS DOCUMENT IS UNLIMITED

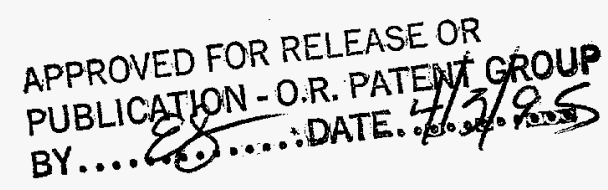




\title{
Report of the SSC Collider Dipole Review Panel
}

\author{
G. Voss \\ Deutsches Elektronen-Synchrotron, DESY \\ Hamburg, Germany \\ and \\ T. Kirk \\ SSC Central Design Group* \\ c/o Lawrence Berkeley Laboratory \\ Berkeley, CA
}

June 1989

* Operated by Universities Research Association for the U. S. Department of Energy. 



\section{DISCLAIMER}

Portions of this document may be illegible in electronic image products. Images are produced from the best available original document. 


\section{Preface}

\section{R. F. Schwitters}

Soon after Universities Research Association (URA) signed the contract with the Department of Energy for management and operation of the SSC Laboratory, I appointed a review panel to examine the ongoing program for development of superconducting collider dipole magnets for the SSC. This program had been managed by the SSC Central Design Group and became the responsibility of URA-SSC in its new role as SSC management and operations $(\mathrm{M} \& \mathrm{O})$ contractor. The report of the SSC Collider Dipole Review Panel is reproduced here.

To combine the independence of an outside review with the detailed knowledge of workers in the program, the review panel was co-chaired by Dr. Gus Voss of Deutsches Elektronen-Synchrotron (DESY) (on leave at the Stanford Linear Accelerator Center at the time) and Dr. Tom Kirk, Head of the CDG Magnet Development Group. Panel members were chosen to represent a broad spectrum of experience in accelerator magnet construction, accelerator physics, high-energy physics, and industrial production and engineering.

The review panel was satisfied with the Collider Dipole Program as it stood at the time of the review, but indicated a number of concerns that they felt must be addressed as the program progressed toward final engineering design and industrial production. Their principal concerns were:

(1) operating margin at the design field and operating temperature;

(2) uncertain performance at the nominal injection energy of $1 \mathrm{TeV}$;

(3) unpredictability of operating field characteristics of production magnets devised from room-temperature measurements; and

(4) need for early systems tests of strings of production magnets.

My staff and I have carefully reviewed the review panel's report and generally accept its comments and recommendations. We have taken steps to ensure that the concerns of the review panel are addressed properly in our ongoing planning efforts. The SSC Magnet Systems Division will use this report as additional guidance for their detailed planning of the remaining collider dipole development effort, final engineering, and the Magnet Industrialization Program.

The Review Panel has provided the Laboratory with sound advice on how to proceed to the final development and industrial production of SSC collider dipole magnets. Their efforts are greatly appreciated by the SSC Laboratory. 



\section{Table of Contents}

Executive Summary

Introduction

Subpanel on the R\&D Program and Industrialization

3

Subpanel on Magnet Measurement

7

Subpanel on Cold Mass Mechanics

9

Subpanel on Superconductor

Subpanel on Cryogenics

Subpanel on Quench Protection

Subpanel on Bore Tube Corrector Coils

Appendix A - Charge to the Collider Dipole Review Panel

Appendix B - Collider Dipole Review Panel Members

Appendix C - Final Collider Dipole Review Panel Agenda

\section{DISCLAIMER}

This report was prepared as an account of work sponsored by an agency of the United States Government. Neither the United States Government nor any agency thereof, nor any of their employees, makes any warranty, express or implied, or assumes any legal liability or responsibility for the accuracy, completeness, or usefulness of any information, apparatus, product, or process disclosed, or represents that its use would not infringe privately owned rights. Reference herein to any specific commercial product, process, or service by trade name, trademark, manufacturer, or otherwise does not necessarily constitute or imply its endorsement, recommendation, or favoring by the United States Government or any agency thereof. The views and opinions of authors expressed herein do not necessarily state or reflect those of the United States Government or any agency thereof. 


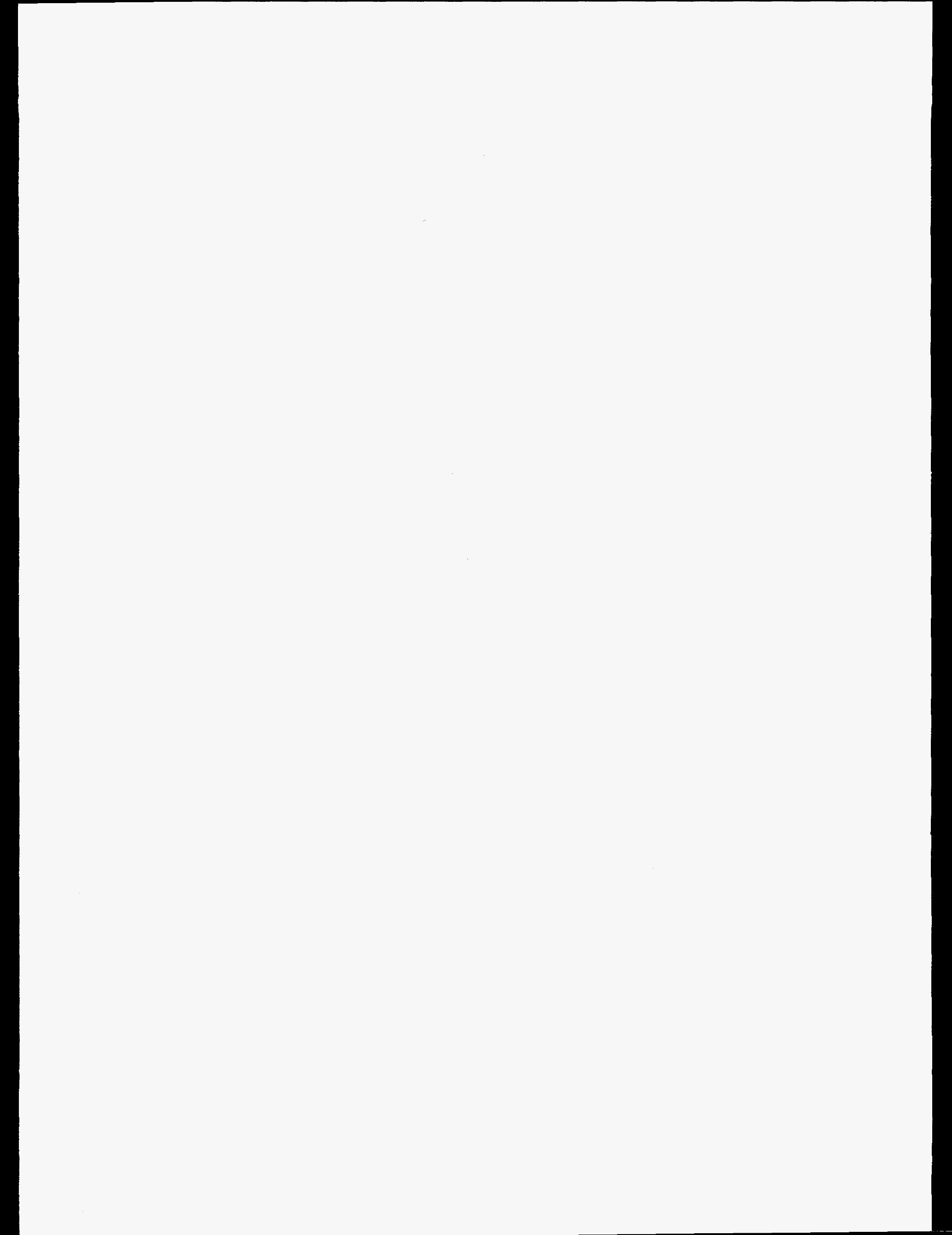




\section{Executive Summary}

The collaboration of Brookhaven National Laboratory (BNL), Fermi National Accelerator Laboratory (FNAL), and Lawrence Berkeley Laboratory (LBL) under the coordination and guidance of the Central Design Group (CDG) in Berkeley, California has been quite successful in the R\&D effort to develop full-scale superconducting collider dipole magnets for the SSC Project. The result of this effort is even more remarkable when one considers the funding limitations during this four-year effort and the difficulty of coordinating the work of the three laboratories involved.

A number of full-length magnets have been built that comfortably exceed the required field level for $20-\mathrm{TeV}$ operation, albeit at lower temperature than specified by the present operating requirements. At intermediate excitation levels they have demonstrated satisfactory magnetic field quality. These magnets are not satisfactory for operation at the 4.3-K defined SSC operating temperature, however, and therefore the magnet design cannot be considered completed at this time. A strong magnet $R \& D$ effort will continue to be required until late 1992 (when the first industrial prototype magnets are scheduled to be built), to solve a number of remaining performance problems. These problems are briefly noted here and developed more fully in the body of the report.

The panel's biggest concern is the insufficient operating field margin for meeting the machine specifications at the highest operating energy. One of the $17-\mathrm{m}$-long magnets actually reached the required field levels for $20-\mathrm{TeV}$ operation at the design temperature, but for trouble-free operation under SSC operating conditions, a 10-percent margin in the operating field before quench should be achieved. Magnets built so far have achieved this desired margin at an energy of $18 \mathrm{TeV}$. If $20-\mathrm{TeV}$ operation is to be preserved, such a margin could conceivably be reached in a number of ways. Lowering the operating temperature might be the easiest way. At the other extreme, if for reasons of machine physics a larger magnet aperture were deemed advantageous, one could think of increasing the superconductor volume at the same time as the aperture is increased to obtain the desired operating margin. Even in this case, the present schedule for the planned start of prototype construction by industry might be kept.

A second area requiring further vigorous $R \& D$ effort is the improvement of field quality at injection energy. Persistent currents in the superconductor cause time-varying sextupole fields which are too large to be left uncorrected. Correction schemes have been worked out on paper, but they need to be designed, built and extensively tested in magnets. Although no major difficulty is foreseen for implementing such schemes, questions of reproducibility of these nonlinear fields from magnet to magnet are still open and need to be addressed.

Note added in proof by G. Voss: It was not in the purview of this panel to consider SSC machine design changes, but it is obvious that higher collider injection energies would greatly alleviate the magnet field quality problems at low excitation.

In this connection, the R\&D effort for continued development of the SSC superconducting cable becomes very important. The highly satisfactory development of superconducting strand with $6-\mu$ superconducting filaments is largely responsible for the fine performance of the present SSC R\&D magnets. If the ongoing R\&D work on $2.5-\mu$ filament strand is successful, the potential problem of non-reproducible persistent currents will be greatly reduced, and with it the heavy reliance on the corrector coils for successful machine operation.

The present plan for cold testing only 10 percent of all the superconducting collider dipole magnets during the production phase also depends critically on understanding the behavior of 
the persistent currents at injection. R\&D efforts here might have a considerable impact on the later testing program. Fabrication in the present R\&D laboratories of a reasonable number of magnets to the present design (built in the same manner and with the same tolerances) remains a critical requirement of the R\&D Program. Subsequent testing of these magnets as a string should also be accomplished as soon as practical. Intensive development efforts here could have a considerable impact on the later testing program.

In summary, the panel feels that the results of the development program so far deserve praise. The dipole design is not finished, however. In order to keep the ambitious schedule of the SSC program (which among other things calls for the first industrially produced prototype magnets by 1992), a continuing strong R\&D effort is necessary and should involve the abovementioned laboratories, industry, and a new magnet test laboratory at the SSC site.

Finally, the Panel wishes to emphasize the importance of the new SSC Laboratory assuming full charge of the $R \& D$ program and managing its resources. 


\section{Introduction}

The Collider Dipole Review Panel was appointed by SSC Laboratory director Roy F. Schwitters on March 23, 1989. One purpose of convening this panel was to provide an indepth review of the collider dipole R\&D program that has been in progress for the past four years in three U.S. DOE laboratories (BNL, FNAL, and LBL), and which has been directed by the SSC Central Design Group in Berkeley, California. The second purpose of the panel was to provide a thorough technical assessment of the current collider dipole design and to evaluate its readiness for release to industry for development of a production version. The charge by Dr. Schwitters to the panel is attached to this report as Appendix A. The panel membership list is attached as Appendix B.

The panel members represent a broad spectrum of expertise, ranging from technical experts currently involved in building superconducting magnets in the U.S. or in Europe to experienced senior managers of technical enterprises, some with and some without a relationship to superconducting magnets. A certain number of scientists with backgrounds less directly related to magnets were also included; these were chosen for their general technical insight and critical abilities.

A minority of the panel members (6 out of 24 ) are currently involved directly in the SSC magnet R\&D program, and hence could be called "insiders." This mix of inside expertise and "outside" critical power was desired by Dr. Schwitters. The mixed panel was found to function together effectively in carrying out the assigned work and in efficiently reaching conclusions.

After receiving the formal charge from Dr. Schwitters, the panel's scope was broadened by the addition of one very significant topic. This was the question of increasing the aperture of the dipole from its current $4-\mathrm{cm}$ value to a new value of $5 \mathrm{~cm}$. There are a number of beneficial technical reasons for considering such a change, but it is anticipated that this change would likely result in cost increases and schedule delays. The panel was asked to comment on both these aspects and has done so.

The panel's working method was extensively discussed by the co-chairmen, Dr. Gus Voss and Dr. Tom Kirk, before any of the meetings of the panel. They concluded, in view of the general desire to reach conclusions on the most rapid practical schedule, that the panel should meet and do its work in one continuous and intensive five-day period. The panel members agreed to this plan (some at significant personal inconvenience), and the panel assembled at the CDG in Berkeley for the period April 17-21, 1989. Most panel members were in attendance for the entire week; all were present for at least the majority of the working time.

Prior to the meeting in Berkeley, the co-chairmen distributed a list of eight discussion topics for consideration by the panel and included under each of these an associated list of subtopics. They identified a suggested set of "convenors" assigned to organize the detailed discussions and subsequent subpanel reports on each of these topics.

Once the topical areas were defined, the panel followed the schedule of working described here. The final panel agenda as it actually evolved is attached as Appendix C. Each day (except for the last) featured early morning presentations by "inside" panel members or by experts involved in the SSC magnet program. The presentations each concentrated on a particular technical aspect of the magnet design. These presentations were followed by subpanel group meetings through the middle of the day. These meetings allowed the experts to explore and discuss together the detailed aspects of their sub-topics. Inside experts not on the panel were provided for the subpanels' convenience as needed and as requested by the convenors. The convenors drafted text on their assigned topics to report the consensus views of the subpanel members. 
At the end of each day, the entire panel reassembled to hear reports on their deliberations from convenors in session that day. Typically, a draft report was distributed by each convenor to the full panel, and a general discussion of that day's text was led by panel chairman Voss. In this way the entire panel was able to contribute to the tone and content of each subpanel report.

By the end of the week, each topic had been considered in plenary session by the entire panel at least once and the text modified to reflect the whole panel's views. These reworked drafts were available to all panel members at the end of the working week.

In the next phase of the panel's work, the co-chairmen brought together the subpanels' written text, a newly drafted introduction and executive summary, a table of contents, and the defined appendices into a (lightly edited) draft report. This draft report was circulated to the entire panel on April 27 for comments. The comments were returned by panel members by May 3 , and a second version was circulated on May 16. Comments received on this version were incorporated in the final version of the report presented here.

The final report was submitted to Dr. Schwitters, as requested, on June 1, 1989. 


\title{
Subpanel on the R\&D Program and Industrialization
}

\author{
(P. Reardon, T. Bush convenors)
}

\section{Introduction}

This panel reviewed issues related to the collider dipole R\&D program, its management, its transition to industry, and the program impact of a major change in the dipole magnet design. The evaluation was based upon information provided in the scheduled topic presentations, comments and discussion from various Magnet Program personnel, and a set of documents provided by the SSC Magnet Systems Division head: SSC Magnet RED Plan 1988, edited by E. L. Goldwasser; Development Status for SSC Magnets, December 1988; SSC Magnet RED Plan Update, January 1989; and the SSC Magnet Program presentations given at the DOE SSC Annual Review, 30 January 1989.

The program goal is to provide a mature design for a $17-\mathrm{m}$-long magnet that is capable of producing a uniform dipole field with an intensity of $6.6 \mathrm{~T}$ at a temperature of $4.35 \mathrm{~K}$ and which satisfies all system requirements but is not yet optimized for industrial production. Further design modifications would be consequences of things learned in the Magnet Industrialization Program (MIP) and the on-going R\&D program. The work would be carried out under the leadership of the SSC Laboratory Magnet Systems Division with directed efforts at BNL, FNAL, LBL, and possibly others.

\section{Adequacy of the Program}

The laboratory-based SSC Magnet Program has in place a systematic approach to the design of magnets meeting SSC system specifications. A two-step process starts with understanding material properties, and analysis is followed by short- and long-magnet fabrication and testing. The subsequent proven design will be detailed in a series of specific process and performance specifications for use by industry. This approach provides for an orderly transition to design and tooling contracts presently scheduled to start in January 1990 and continue through the period when production contracts are to be awarded. The development logic is consistent with this process and if rigorously followed will provide a magnet design for production. Presently identified development issues are being worked out, and there is a provision to handle additional issues uncovered in the development program. The use of short and long magnets is a cost- and schedule-effective approach to the development program. The R\&D managers are setting proper and appropriate goals and are well aware of the program progress. Given the inherent difficulties in meeting the requirements of the SSC collider ring, the innovations required, the technical and managerial difficulties that had to be coped with, the $\mathrm{CDG} / \mathrm{BNL} / \mathrm{FNAL} / \mathrm{LBL}$ collaboration that has brought the design to its present state of maturity has much to be proud of. It is a fine technical accomplishment.

\section{Comments on the Present Design}

Significant development and testing needs to be done before this design is ready for start of contractor prototype production in 1992. The following should be completed by the beginning of full production in 1992. 
1. "Prime Item Requirements Document"

2. Testing to demonstrate achievement of design requirements

3. Development magnet string test to demonstrate system performance

4. Magnet life cycle testing

In addition, three design concerns should be addressed:

1. The design margin

2. Production tolerances

3. Demonstration of sufficient correlation between warm magnetic measurements and cold magnetic measurements to justify the present plan to cold measure only ten percent of the production magnets

\section{Magnetic Field Design Margin}

The panel considers the present margins too low for the specified operating field of $6.6 \mathrm{~T}$ at $4.35 \mathrm{~K}$. The question of margin can be addressed in a number of ways and includes the specification for the number of quenches required to achieve operating field or establishment of a margin that assures that the first training quench occurs above peak operating field. Of the several approaches to establishing the design margin, those involving significant changes to the present cross section appear to be most disruptive to the present R\&D program, unless the cross section has to be changed for other reasons. The panel emphasizes that each of these approaches requires significant analysis, engineering, and/or R\&D before adoption.

\section{Production Tolerance}

The issue of establishing production tolerances that will guarantee operating performance of the 8000 dipole magnets is a difficult one to resolve without the fabrication and testing of a number of magnets built to essentially the same design and with controlled fabrication approaches. The present R\&D plan for building 20 dipole magnets per year at FNAL/BNL should be vigorously pursued. The SSC Magnet Division should review the number and use of $R \& D$ magnets to ensure consistency with program goals. The present dimensional control and magnet measurements capability on critical cold-mass components is impressive. Insufficient data exist to calibrate present approaches to set the base-line tolerances required for industrial production. These will have to be acquired during the early industrialization phase.

\section{Warm/Cold Measurements}

The program to compare magnet measurements at room temperature with those at liquid helium temperature is just beginning. The measurement techniques themselves are indeed promising, but adequate knowledge of the differences to be expected and the means to make valid comparisons does not yet exist. A broader statistical base is required, particularly in the use of measurements on superconducting cable to determine the effects of persistent currents on the sextupole effects of magnets built from those cables. 


\section{Industrialization}

The panel noted that two industrialization plans have been followed, one for superconducting wire and cable and one for dipole magnets. In both cases the panel felt the plans themselves were well thought out and provided an excellent starting point for developing the industrial infrastructure required to produce the 8000 superconducting dipole magnets for the collider.

Approval by DOE for the initiation of Phase I of the MIP was received on July 21, 1988, and this enabled the program to be activated. The magnets and associated tooling currently being produced at BNL and FNAL represent an adequate state of development to support Phase II of the MIP, now scheduled to start in January 1990. Development of production magnet designs and tooling by the SSC Magnet Division lab-industrial team will address the key issues of production tolerances, quality assurance, quality control, and acceptance testing.

The panel supports SSC Magnet Division management in their plan to proceed with the selection of the magnet industrial contractors on the present schedule with the presently available design data. The panel believes the earliest practical introduction of industry into the MIP will be in the best interest of the program.

Note added in proof by P. Reardon: Since the final choice of filament size has not been made, however, plans for scaling up industrial production of superconducting wire and cable should be reevaluated in light of the $R \& D$ progress on filament size and design requirements to minimize the effects of persistent currents.

\section{Comments on Changing Aperture Size}

The panel reviewed the magnet development and production program and provided considerations that must be addressed in order to continue program momentum if an aperture change is introduced into the present dipole magnet design.

Alternate programs were considered. In every case considered, the assembly, testing, and development of the 4-cm design would continue in order to provide a proven 4-cm backup design as well as essential data for the $5-\mathrm{cm}$ design. The $4-\mathrm{cm}$ design would be continued until the $5-\mathrm{cm}$ design is reasonably tested.

If a redesigned magnet is to be thoroughly tested prior to the start of the Phase II MIP, it is likely that a delay of two years could occur. Although this appears on the surface to be the least risky program for changing the aperture, the loss of momentum from the delay in starting transition to the industrial team would be very costly.

Alternatively, it was determined that a program keeping the start of Phase II on the present schedule (January 1990) could cost the least and provide the earliest delivery of dipole magnets from the production lines. Under strong leadership, a dedicated team of experts in the present $4-\mathrm{cm}$ design would develop a $5-\mathrm{cm}$ design. The tooling design would be started at one of the laboratories with the expectation that it would deliver the first $5-\mathrm{cm}$ cold mass twelve months after the magnet design is accepted by the SSC Magnet Division head.

The industry team would be given the $5-\mathrm{cm}$ design for use during MIP Phase II at contract award. Concurrently with the MIP Phase II, the designated laboratory would provide short and long $5-\mathrm{cm}$ aperture magnets for engineering evaluation and further development. Each contractor would be required to support this further development such that the emerging design could be introduced in an efficient manner into the various magnet contractor programs. This approach seems to offer the least overall program risk, although it must be carefully laid out and reviewed before start. 
For any program, a detailed update of cost and schedule modifications should be conducted concurrently with the design effort.

\section{Management}

The SSC Magnet System Division is programmed to select and manage five magnet contractors, five wire manufacturers, and three laboratories. This is a much greater number of magnet contractors than have been required of other high-energy accelerator enterprises. The committee feels that the establishment of the necessary management infrastructure in full control of all aspects of the magnet design, analysis, contracting, QA, testing, etc., is critical. Administrative support should be made available to assist in the hiring of additional staff. The SSC Laboratory must be the prime interface with the industrial contractors and must establish at its site the engineering, analysis, contract management and other staff necessary to execute the task. In developing the new site infrastructure, it is critical to the success of the magnet development effort that the existing institutional memory and key individuals be incorporated into the new program. The SSC Laboratory should have complete control to negotiate subcontracts with participating laboratories and industry for performance of the R\&D work.

Note added in proof by P. Reardon: Also, the SSC Laboratory should have sufficient inhouse measurement and $R \& D$ fabrication capability to verify the progress of its industrial subcontractors and provide technical guidance to them as the program progresses. 


\title{
Subpanel on Magnet Measurement
}

\author{
(A. Tollestrup, K. Halbach convenors)
}

The panel considered a number of questions relating to the magnet measurement program and identified some areas that need attention. We did not discuss the organization or the facility needed to carry out the measurement program, but rather concentrated on some technical questions. An underlying theme of the discussion involved the need to know the relative values of the low order multipoles from magnet to magnet with the following accuracy:

TABLE 1

\section{Multipole \\ $a_{1}, b_{1}$ \\ $a_{2}, b_{2}$ \\ $\mathrm{a}_{3}, \mathrm{~b}_{3}$}

\author{
Measurement Accuracy \\ 0.4 units* $^{*}$ \\ 0.2 units \\ 0.05 units (absolute accuracy)
}

*One unit $=1.0 \times 10^{-4}$ field deviation relative to the dipole component at a radius of $1.0 \mathrm{~cm}$.

These measurement tolerances are smaller than the permitted random fluctuation in the magnets as constructed. The reason is that in order to cancel the effects of random fluctuations the magnets must be measured and then installed in a sequence that minimizes the effect of the random fluctuations. For this process to succeed, the measurements need to have the accuracy as indicated in Table 1. With this as background, we proceed to several different topics.

\section{Persistent Currents}

Persistent currents and their time decay in superconducting magnets are poorly understood. They are not present in warm measurements, and hence, unless they can be accurately controlled, the cold $\mathbf{b}_{2}$ multipole cannot be predicted. We also heard evidence that the time decay of the magnetization depends on the manufacturer of the cable, which indicates a sensitivity to the superconductor processing. Since the chromaticity of the SSC is such a sensitive function of $b_{2}$, it is imperative that these effects be understood, reduced, and the variables affecting them be controlled. As a result we suggest:

1. An $R \& D$ effort to develop tests that can be done on the composite superconductor wire that will allow prediction of $b_{2}(t)$ in a completed magnet from measurements made only on the wire. This is essential for quality control of the magnets.

2. The R\&D program must identify the processing variables that affect both the magnitude and time dependence of the magnetization. The question of whether the wire 
specification will need to include only finished product parameters or will also need to specify the actual processing schedule needs to be addressed.

3. Specification for a standard test of $b_{2}(t)$ needs to be developed. This standard will allow various laboratories to compare results and machine designers to make pertinent calculations.

\section{Warm versus Cold Measurements}

Our understanding of the present magnet production plan is that all magnets will be measured warm and some fraction ( 10 percent) will be measured cold. All pre-production magnets will be measured cold to establish the warm/cold correlation base.

The evidence we heard, coupled with the numbers shown in Table I, indicate that the correlation between warm and cold measurements is not good enough yet to allow such a measurement schedule even if the persistent current questions discussed above are excluded. We recommend:

1. A careful study to uncover why the warm and cold measurements differ:

a. Do the multipoles shift by more than the amount indicated in Table 1 with training?

b. Study the pros and cons of vertical versus horizontal split in the iron yoke as this pertains to the multipole behavior.

2. The stability of the vertical plane in completed magnets needs study. We note this measurement program is starting.

\section{Multipole Measurements}

The SSC will have to set up a strong measurement facility. It should take control of the hardware development and specification as soon as possible. Uniform hardware will have to be available as soon as the industrialization is started.

Standard instrumentation for field, $a_{n}, b_{n}$, persistent current fields and their time dependence, vertical plane, and end fields must be specified as well as calibration standards. Note that Table 1 requires $b_{2}$ measured to an accuracy of 0.2 units out of 8 , or 2-1/2 percent.

Note added in proof by P. Schmüser: The problem of yoke saturation ( 3 percent at $6.6 \mathrm{~T}$ according to C. Goodzeit) was not discussed. The saturation will surely influence the multipoles. No measurements were shown at high field.

Note added in proof by H. Kaiser: The close proximity of the yoke iron to the coil furthermore leads to a 3 percent saturation of the dipole field at $6.6 \mathrm{~T}$ (measured value). With dipoles and quadrupoles electrically connected in series (as in HERA and the Tevatron), rather strong quadrupole correctors will be needed to achieve tracking. The sum of the costs of the dipole and correctors might have its minimum at a lower value of dipole saturation. The higher-order multipoles also need to be measured at $6.6 \mathrm{~T}$ to verify that the influence of iron saturation is tolerable.

Note added in proof by $A$. Tollestrup: The saturation value of the sextupole field at $6.6 \mathrm{~T}$ can be compensated by the proposed sextupole correction scheme. The variation in the saturation properties can and must be controlled in the yoke iron by maintaining the carbon content below 0.05 percent. This restriction will maintain the sextupole variation within the allowed random sextupole tolerances over the entire saturation regime. 


\title{
Subpanel on Cold Mass Mechanics
}

\author{
(H. Kaiser, R. Perin, R. Huson convenors)
}

The review concentrated on the present design. The components and related forces of the cold mass and their interfaces were reviewed first and then the whole system was reviewed under the conditions of assembly, cooldown, and operation.

\section{Beam Tube}

The beam tube is located transversely by guides engaging in grooves in the coil collar. No contact exists with the main coil. The review of the attachment of guides to the beam tube and their alignment relative to beam tube correction coils was left to the Correction Coil Subpanel. Longitudinal location in a chain of dipoles consists of nothing but the beam tubes interconnected by bellows. To avoid longitudinal moving of the beam tubes (possibly during thermal cycles), the reviewers recommend longitudinal fixation of the beam tube to the end plate at the leads end of each magnet.

In the proposed junction of the beam tubes between adjacent magnets, the panel recommends that the vacuum protecting the inner bellow from contact with single-phase helium be extended over the weld connecting the beam tube and bellow sleeve. This will safeguard against helium penetrating the beam vacuum at this weld.

The panel was concerned about the small fraction of 0.01 of total helium mass-flow passing through the 1-mm annular gap between correction and main coils. With the new "transverse cooling scheme" to be tried first on dipole DD0019, this problem should be solved. The local helium gas pressure rise due to quench will not exceed 20 bar.

The need to continue monitoring the magnetic susceptibility of the beam tube material was emphasized; this applies to the collar material as well, including the stainless-steel tubes connecting the collar packages.

\section{Coil Ends}

Some magnets are still subject to short circuits that are frequently located at the ends. A currently applied cure is the insertion of molded glass-epoxy spacers or pre-preg bands on virtually each conductor turn, to locally reinforce the insulation; this does not appear to be an economical solution for mass production in industry because it is time consuming and requires a large variety of spacers that must be individually positioned. Solutions to this problem should and are being sought. An improvement of the conductor insulation mechanical strength would be very beneficial. It is also recommended to reduce the number of end spacers and to avoid sharp or too thin edges that might break off and damage the insulation-this last danger was deemed less for spacers machined from G11 as used for HERA coils. It is noted that a larger coil aperture would allow larger curvature radii and ease the problem.

Note added in proof by $H$. Kaiser: G11 spacers also match the thermal contraction of the coil better than cast epoxy spacers with relatively low glass fiber content.

The longitudinal confinement of the coils is partly given by thick end plates joined to the helium vessel, partly by frictional forces between coils and collars and collars and the helium 
vessel. This complex situation is not present in the Tevatron or HERA dipoles and could conceivably contribute to the observed training behavior of the SSC magnets. This area is under intense investigation by the magnet group. The panel encourages a continuation of these studies.

\section{Coil Loading, Clamping Force, Mechanical Support Structure}

Electromagnetic force distribution and the general principle of coil support to prevent premature quenching and training are well understood, and the available computational tools adequate. In the design of optimum solutions there are, however, some limitations. One severe limitation comes from the radial space available for the collars, which was apparently imposed to the designers of the mechanical structure a long time ago. This precludes the use of aluminum alloy for the collars, as they would be too thin to withstand the magnetic forces. Even if a great part of these forces are taken by the yoke/skin assembly, aluminum alloy collars appear difficult to use because they would deform too much after collaring to allow easy assembly of the yoke halves around them.

The designers did their best within the imposed limit, but they were compelled to use sophisticated high-strength materials (Nitronic 40, high-manganese steel) having less favorable thermal contraction. The consequences are higher collaring compression and higher creep in the coils at room temperature. The panel recommends that such limitations, which were perhaps justified in the past, be reexamined.

Concerning horizontal or vertical split of the iron yoke, the panel finds that functionally the vertical split is more efficient in limiting the deformation of the coils, thus decreasing the level of the needed initial prestress. Vertical split is also better from the point of view of field quality. If, however, the gap between yoke halves is completely closed at room temperature after welding of the skin, there is no difference between vertical and horizontal splits, except that with the vertical split the contribution of the skin to the support of the magnetic forces will be higher.

At present the designers seem to prefer the horizontal split yoke. No vertical split yoke assembly has been tried so far for the SSC magnet. The reason is that the mounting of yoke halves around the "elliptically" deformed coil/collar assembly is easier. It is also intended to close the gap at room temperature by strongly pressing the yoke halves together before the outer skin is welded. The reproducibility of the geometry between warm and cold conditions will then be better ensured, but it is not clear how the collar/yoke contact in the region of the horizontal median plane is maintained, a necessary condition for a reliable support of the collared coil by the yoke. The proposed solution assumes line contact and is based on the use of high-manganese steel for the collars. This material has a thermal contraction lower than the iron of the yoke. The panel notes, however, that with collars of this material the coils will lose a larger fraction of their initial prestress than with aluminum or stainless-steel collars at cool-down. It must be verified that the remaining prestress is still sufficient and that the higher needed collaring prestress is not too high or does not vanish due to creep. Attention is called to the fact that the magnets have to be stored at room temperature for a long time.

It is also stressed that the use of high-strength materials in components with notches needs verification of soundness under fatigue.

Furthermore, it is remarked that if the yoke halves do not close symmetrically on both sides (e.g., because of skin/yoke/collar/friction), the gain in prestress on the coils will not be achieved as foreseen, with adverse effects on mechanical stability and field quality. 


\section{Alignment and Survey}

The alignment system starts in the beam tube. A cross hair centered on the beam tube is used to reference four circumferential points on the outside of the cold mass at each of the five posts. The field direction is referenced from exciting the magnetic field with $10 \mathrm{~A}$ (accuracy of $0.1 \mathrm{mrad}$ ). This is transferred to the foot of each post to have reference outside the vacuum chamber. The center post of the magnet is welded to the cold mass, the other four posts locate the magnet in transverse dimensions, but not in longitudinal position or rotation.

There are many transfers of coordinates from one point to another. This gives a potential of making errors in alignment. More direct reference from cold mass to outside should be considered. This could allow alignment by adjusting posts from outside and perhaps cost reduction.

The sagitta of the magnet is obtained by positioning the posts. This requires a horizontal force on the post of about $40 \mathrm{lb}$. The posts are positioned by using shims.

The posts have been extensively tested. They are tied rigidly together by filament-wound graphite rods which have essentially zero contraction during cooldown. These rods are strong enough to hold the magnets at an angle for insertion into the tunnel. The sliding of the cold mass on the noncentral posts takes place on a teflon-impregnated brass piece (the coefficient of friction is 0.3 cold). Tests of radiation damage to these pieces must be made, and the total accumulated radiation dose needs to be determined.

Alignment procedures have been studied, but not tested. It will be necessary to test stability of alignment of the cold mass to outside reference under fatigue, transport, and time (creep). The impact of the length of the magnet on alignment has not been studied. The effect on alignment of a quench giving 20 bars pressure in the magnet must also be studied.

\section{Technical and Cost Impact for Changing Aperture from $4 \mathrm{~cm}$ to $5 \mathrm{~cm}$}

In this section we discuss the mechanical and magnetic consequences of an aperture change from $4 \mathrm{~cm}$ to $5 \mathrm{~cm}$. We use the SSC Central Design Group report Compensation of SSC Lattice Optics in the Presence of Dipole Field Errors, SSC-SR-1038, and Cost Comparisons for SSC Magnet Dependent Systems, SSC-SR-1012. In the first study done three years ago, the estimated cost increase for the dipoles was 16 percent; we did not review this estimate. If the aperture is changed, other design changes should also be considered, e.g.

\section{Aluminum Collars}

2. Coil geometry changes to allow more superconductor, etc.

The consequences of the change identified by the panel include:

1. Field. Increasing the coil aperture not only reduces the effects of persistent currents but also reduces systematic and random magnet errors. In general, the nth-order multipole effect scales as the nth power of the radial distance ratio.

2. Tolerances. Cable placement is less critical by approximately 15 percent to achieve the same field quality. It is hoped that the mechanical position tolerances would remain the same, and the improvements mentioned could be obtained.

3. Forces. Lorentz forces are increased approximately linearly. 
4. Ends. The ends of the 4-cm magnet are quite complicated. The larger radii at the ends for the 5-cm aperture will permit simplifications.

5. Body. The larger cross section for 5-cm aperture provides more freedom for layout of cable and wedges, and facilitates fabrication.

6. Quench Protection. The energy per unit length is about 50 percent higher and thus the length of each magnet may be limited to less than $17 \mathrm{~m}$ in a passive quench system without heaters.

A detailed study needs to be done before a more complete assessment of these factors can be made.

Even if the aperture is changed to $5 \mathrm{~cm}$, the $4-\mathrm{cm}$ aperture long magnet work should be continued for a certain number of identical magnets to establish reproducibility within specifications for magnets that reach a current near the short sample value. This will also serve as a backup for the 5-cm program.

\section{Concluding Remarks}

The cold-mass design was the subject of remarkably steady progress for the course of the last three years thanks to a sustained and admirable effort by the designers, builders, and all other involved persons. The panel, however, considers that given the present boundary conditions, this design has now been pushed very close to its performance limits and that further significant improvements will be painful to obtain. In the panel's opinion, the present performance level does not guarantee a sufficient performance margin for reliable operation of the present design at $20 \mathrm{TeV}, 4.35 \mathrm{~K}$.

The panel believes that given the present characteristics of the envisaged superconducting cable, such a necessary margin can be gained by changes either in the magnet cross section, in operation temperature, or in machine circumference.

The 17-m magnets should in a few training steps come near to the short sample current and exhibit no appreciable retraining. The reasons why the magnets built so far do not quite reach this goal need to be identified and eliminated. After this, a few magnets with identical design should be built to verify reproducible achievement of the goal.

This program should be completed for the 4-cm magnet, even if a change to the 5-cm bore is decided, for reasons of proving the current basic design to be sound and for providing a fall-back solution in case of problems with the $5-\mathrm{cm}$ magnet. 


\title{
Subpanel on Superconductor
}

\author{
(R. Lundy, F. Asner convenors)
}

\section{Introduction}

The properties and performance of the superconducting cable that will be utilized in the SSC magnets are of crucial importance. The cable itself is roughly 10 percent of the direct cost of the project and because of its leverage on other design features such as magnet strength and size strongly influences total project cost.

This same leverage requires that the performance and physical properties be well understood and kept constant at an early time in the project life cycle. Improvements and new developments that will certainly come along during the construction process will in many cases prove impossible to incorporate because of the need to make magnets that are as nearly identical as possible. For this reason the panel recommends that the superconductor R\&D efforts discussed below be given very high priority and the necessary resources as soon as possible with the understanding that this effort will be able to be reduced markedly once production starts for the final magnet design. Response to the questions presented to the panel and other observations are grouped under the following headings:

1. Procurement and specification policy

2. Conductor parameters and prospects for improvement

3. Operating margin

4. Impact of a change in magnet aperture

5. Insulation scheme

6. Quality control

\section{Procurement and Specification Policy}

The work during the last few years to improve the performance of niobium-titanium superconducting alloys has been very successful, resulting in an least a 50 percent improvement in $\mathrm{J}_{\mathrm{C}}$ the critical current density. Nonetheless, this same work as well as the production experience of cable for HERA indicates that we still lack a complete understanding of the many variables involved in cable manufacturing. In some areas, such as the magnetization of cable due to persistent currents and the possible variation of the time dependence of such currents, we have no knowledge of what different manufacturing methods may introduce as complications.

The panel believes that the only prudent approach to this problem is for the SSC Laboratory to carry out enough critical R\&D tests (in conjunction with all appropriate vendors) to be able to tightly specify all process steps in the manufacture of the superconducting cable. It will be very unlikely that our knowledge will be so advanced in the remaining time that it will be possible to define performance specifications and to permit vendors to employ varying methods of manufacture hoping that the end products will be identical in every way that is 
important to magnet performance. This approach puts a heavy burden on the SSC Laboratory. It will have to be deeply involved in the monitoring and testing of the cable and will have the final responsibility for the quality of the material which will ultimately be supplied to magnet manufacturers. This panel is not qualified to assess all the implications of this approach, but it seems clear that it will have an impact on the overall industrialization effort of the SSC Laboratory.

Note in proof by G. Voss: The procedure suggested here obviously has the potential of producing many technical and contractual problems. The first priority, therefore, should be (1) an $R \& D$ program to study the parameters that affect the magnetization and its time dependence, and (2) to develop, as mentioned earlier, a measurement on the composite superconductor wire that allows prediction of the $b_{2}(t)$ (time-dependent) behavior of a magnet.

\section{Wire and Cable Specifications}

The present versions of the specifications are useful and adequate for the $R \& D$ program. However, several areas need improvement before the specifications will guarantee that the cable suffices for accelerator quality dipoles. The area in most need of improvement is control of persistent current effects. Either a definitive test for predicting $b_{2}(t)$ must be developed for the strand and cable, or the specification must be modified to provide control of magnetization effects through specification of processing parameters. Both approaches should be pursued in the R\&D program until a clear solution emerges.

\section{Filament Size R\&D Plan}

During the last two years, a $6-\mu \mathrm{m}$ filament diameter has been the main approach, with a 9- $\mu \mathrm{m}$ filament as a "backup" and a 2.5- $\mu \mathrm{m}$ filament diameter the subject of a small-scale R\&D effort. At this time, it has been demonstrated to a sufficient degree that the SSC conductors can be made successfully with a $6-\mu \mathrm{m}$ filament size. Consequently, the backup program involving a 9- $\mu \mathrm{m}$ filament size should be dropped, and more resources used to speed the development of a $2.5-\mu \mathrm{m}$ filament conductor. This is true especially in light of (a) the promising results in eliminating proximity effect coupling with the $\mathrm{Cu}$ with 0.5 percent by weight $\mathrm{Mn}$ matrix between the filaments, and (b) the recent results from Furukawa presented at the IISSC with $2.5-\mu \mathrm{m}$ filaments.

\section{Magnet Operating Margin}

The panel believes that the parameters discussed above and their most likely development will not provide enough improvement so that the present magnet design will routinely achieve a maximum field of at least 10 percent more than the operating field of $6.6 \mathrm{~T}$ at $4.35 \mathrm{~K}$. Such an improvement can be reached by taking advantage of reduced-temperature operation or by redesigning the magnet cross section so as to incorporate more superconducting material, for example by designing new cables with a larger number of strands and thus an increased width. The SSC laboratory must evaluate the cost and operational tradeoffs between these two methods or some combination of them. The panel estimates that superconductor costs would increase by roughly 25 percent for a 10 percent increase in operating field, but we are not in a position to tabulate the costs of other required design changes that a wider cable might demand. The required temperature drop to achieve the same field increase, the refrigeration 
equipment cost increase, the possible cryostat redesign costs, and the relative importance of future increased operating costs must be supplied by qualified experts.

We do note that two concerns relating to reduced temperature operation exist: namely that the changes in quench propagation velocity and in specific-heat of materials may lead to magnets that reach higher peak temperatures and suffer damage. The most likely source of quenches in operation will be undesired beam loss (as demonstrated in the Tevatron).

\section{Impact of a $4 \rightarrow 5 \mathrm{~cm}$ Aperture Change}

The advantages of an increased magnet aperture are being evaluated from other points of view, and the panel limits itself here to the following observations:

1. A larger aperture dilutes most construction dimensional errors and thus produces better magnets from a multipole point of view.

2. The increased radii of curvature in the ends is a help in fabrication.

3. It is expected that any new cable required could be fabricated from existing strand designs or designs very close to those being developed. The number of strands in each cable should probably increase (perhaps due to operating margin requirements as well) and may lead to a need for cabling machines with a larger strand number capability than the recent DOUR design. Such cables can be made on other existing machines with subsequent production machines being ordered as required.

4. The time delay due to the above is almost certainly less than the delay that would ensue from other magnet part redesigns and procurements and in any case is expected to be no more than three to four months.

\section{Insulation Scheme}

Cable insulation appears to be well developed at this time and the committee has no specific recommendations for changes. The insulation consists of a wrap of $0.001 \times 0.375 \mathrm{in}$. Kapton with a 50-percent overlap, giving two layers of insulation. This is followed by a wrap of epoxy-impregnated fiberglass about $0.004 \times 0.375 \mathrm{in}$. with a gap of $0.020 \mathrm{in}$. between adjacent turns.

Application of insulation to the cable is critical to the successful operation of the magnet and will require careful quality control throughout the magnet construction period. Some of the important concerns apparent to the committee are:

1. Since the epoxy fiberglass has limited shelf life, careful control must be instituted to ensure that it is properly stored prior to use, and that it is applied just prior to winding the cable into a coil.

2. Cleanliness and freedom from burrs on the cable is of extreme importance.

3. Tension during winding must be carefully controlled. 


\section{Quality Control}

The discussion of the procurement/specification policy indicates that the SSC Laboratory will prescribe and be actively involved in a comprehensive quality control program. The techniques and instruments involved in this program have been refined or invented during the R\&D program, and we expect that developments now under way will yield an adequate set of tools for this job. Some measurements and devices that will be employed are:

1. Raw materials will be tested against standards with existing industrial methods for chemical analysis and dimensional checks.

2. Strand diameter can be 100 percent monitored with existing laser micrometers.

3. Cable dimensions are nearly 100 percent verified by on-line measuring devices of the type developed at FNAL and now in use.

4. Critical current measurements for strand and complete cable have been refined and can yield information about filament uniformity as well. These tests are only sampling tests at about the $10^{-3}$ level and it may be necessary to apply them at a higher level.

5. Magnetization and time dependence can be measured on small samples with techniques now being developed. These must be fully refined and incorporated as routine $Q C$ checks.

6. Copper RRR and various mechanical properties of finished material can easily be sampled and these measurements will have to be incorporated as a standard part of the QC program.

7. A continuous eddy current check should be performed on all strands and on the finished cable. 


\title{
Subpanel on Cryogenics
}

\author{
(M. McAshan, T. Kozman convenors)
}

\section{Conclusions and Recommendations}

A considerable amount of the design work and proof of principle has been successfully accomplished. The results of the cryogenics design so far look encouraging and indicate the overall heat load requirements can and will be met. Improvements (to gain manufacturing tolerance) can be made during the final $R \& D$ period with the industrial contractors. We recommend that industrial involvement with these components begin as soon as possible. Industrial involvement can help with the manufacturability and cost sensitive components.

There are several things that need better definition prior to production in the R\&D effort. These include:

1. The seismic criteria need to be reexamined, particularly with respect to the present site selection.

2. Transportation loading criteria and installation loading criteria need to be reviewed for possible design differences as these are now measured experimentally. It is our understanding that this work is currently in progress both analytically and experimentally.

3. A heat load test on a series of magnets needs to be accomplished during the "scheduled" string test.

4. Fatigue and creep analyses should be performed on critical components such as posts and tie bars.

5. Thermal distortion measurements and failure analysis should be performed for major components.

6. Prior to production, the entire cryostat system should have an independent mechanical analysis check of the then-current design.

7. System safety studies need to be performed with the materials used for the presently defined cryostat.

Other specific questions are addressed below:

1. Discuss synchrotron radiation heat load, impedance load, and heat transfer.

It appears the present temperature distribution across the conductor is $0.167 \mathrm{~K}$ higher than the mean helium flow temperature without connection cross flow considerations from synchrotron radiation. This can be reduced below $0.05 \mathrm{~K}$ with the Shutt parallelflow cooling discussed below. No real design has been carried out for the beam pipe bellows impedance liner. 
2. Discuss the chosen technical solutions for interconnections, vacuum vessel, bellows, sealing techniques.

A thorough analysis of elastic stability and interconnection mechanics needs to be completed. In addition, the bellows design for the interconnect needs another iteration.

3. What would the impact of a $5-\mathrm{cm}$ bore size decision be technically and with respect to cost differential.

The weight gets larger and heat load for each magnet will increase. The size of the cryostat will grow since the clearances are scaled to the present assembly methods and sizes employed. In addition one could consider different cooling schemes if a larger bore is chosen.

4. Comment on the desirability of lower temperature SSC operations ( $3.5 \mathrm{~K}$ ?) and on its cost impact.

Requires a larger gas return line (perhaps 4 in.). This will require some changes in the current cryostat design but the cost impact is expected to be small.

5. Comment on magnet cooldown with the Shutt parallel-flow cooling scheme.

This does not appear to be a problem with the presently planned system mass transfer and could be a good way to help lower conductor temperature. This idea needs to be examined further to see if the gain is significant with manufacturing tolerances considered. To date, only a static pressure analysis has been performed. A full-scale test should be performed with simulated beam heating sources as soon as possible to verify the expected cooling performance. 


\title{
Subpanel on Quench Protection
}

\author{
(R. Kephart, H. Lynch convenors)
}

\section{Quench Protection}

This group examined a number of issues relevant to protecting SSC dipole magnets from damage in the event that the magnet's superconducting coil quenches. The proposed quench protection scheme is described in the 1986 SSC Conceptual Design Report (CDR) and depends upon an active quench detection system consisting of detection circuitry, heaters located in each magnet, and safety leads located in each half cell of the machine. The safety leads provide a path through which to remove energy from the entire magnet string should any magnet in that string quench. Electrically fired heaters in each coil are used to rapidly spread the quench over the entire coil. This ensures that the magnetic stored energy is distributed over a sufficient amount of material in the coil such that the resulting maximum hot spot temperature is kept below that which might result in damage.

In addition to this protection scheme, several others are under investigation for use at the SSC. The most notable alternative involves the use of cold (4-K) bypass diodes across the leads of each magnet to ensure that each magnet absorbs only its own stored energy. One advantage of such a system is that it could potentially serve as a purely passive system that is intrinsically safe from both magnet damage and accelerator interruptions due to failures of active quench protection electronics. The panel notes, however, that other uncertainties exist in employing this technique. In particular, the technical problems associated with using such diodes immersed in liquid helium must be solved. Although there appear to be no problems for the lifetime, there are significant uncertainties as to how these diodes would behave in the high radiation environment around the SSC dipole. In addition, statistics on the base reliability of diodes and the consequences of diode failure need careful examination. While this passive scheme may be adequate for the machine as presented to the panel, it is unlikely to be adequate to protect a machine having larger stored energy or lower temperature.

The panel endorses further R\&D to explore this technique but feels strongly that the heaters in present $R \& D$ magnets should be retained, at least until such time as a final solution is chosen and verified in string tests. In addition, the panel strongly encourages detailed tests of the quench properties of strings of SSC dipoles at the earliest possible time. The group further notes that there appears to be no significant cost difference associated with building the scheme in the CDR over a cold diode scheme, and that the high-energy booster probably needs an active quench protection system. Furthermore, the additional cryogenics load required to supply refrigeration for the safety lead cooling is expected to be quite small ( $\leq 15$ percent of the total lead flow).

The test data shown to the panel on the calculated hot spot temperatures for various recently built $R \& D$ dipoles indicate that the maximum temperatures observed in a quench, while large $(\sim 500 \mathrm{~K})$, are nevertheless acceptable for the current $4-\mathrm{cm}$ aperture magnets when operated at $4.3 \mathrm{~K}$. Since the hot spot temperature depends on a number of variables, conductor cross section, stored energy, velocity of quench propagation (and therefore $\mathrm{I} / \mathrm{I}_{\max }, \mathrm{Cu}: \mathrm{SC}$ ratio, and operating temperature), the panel believes that any change in these variables that increases $T_{\max }$ much above its present value is undesirable from the standpoint of quench protection. 
As a result, decisions to operate the existing magnet at lower temperatures or to increase its stored energy by opening the aperture to $5 \mathrm{~cm}$ will probably require other modifications to insure that $\mathrm{T}_{\max }$ remains in an acceptable range.

Data presented on the temperature rise as a function of magnet quench current for different Cu:SC ratios show a difference of only $25-50 \mathrm{~K}$ when the $\mathrm{Cu}: \mathrm{SC}$ ratio varies from 1.2 to 1.6 . As a result this parameter does not appear to play a very important role for quench protection in the region of interest.

An appropriate amount of redundancy is needed in the quench protection circuitry to assure the detection of a quench while preventing false alarms, and to assure proper action is taken in case of real quenches. Work is needed to properly define these needs.

\section{Other Action Items}

1. The panel recommends a careful evaluation of all materials in the SSC dipole coil (conductor, Kapton, epoxy, filler blocks, solder, joints, etc.) to develop a specification for the maximum permissible $\mathrm{T}_{\max }$ for the SSC dipoles.

2. The panel recommends that a development schedule be worked out that leads to prototype protection systems available for testing on the proposed SSC magnet string tests. The group was not provided with detailed plans for these string tests but endorses the concept of such tests. We further urge that they receive the manpower and budget necessary for them to provide timely operational information to the rest of the R\&D program.

3. The panel feels that a careful study to determine the mean time between failures of the final SSC quench protection system is important.

4. The panel recommends that more theoretical modeling work be done to predict quench behavior. This would allow calculations to be applied to different magnet designs in a timely fashion.

5. More work on heater design and placement is in order. 


\title{
Subpanel on Bore Tube Corrector Coils
}

\author{
(P. Schmüser, J. Rees convenors)
}

\section{Status of Design, Materials, and Fabrication Methods}

In the present design, bore tube correctors are foreseen to compensate the persistent-current sextupole of the main dipole, the sextupole caused by geometrical imperfections, and sextupole caused by saturation. The sextupole corrector is $10-\mathrm{m}$ long and is mounted on the cold beam pipe. It consists of three subcoils which are wound on a plastic substrate using the so-called "multiwire" technique. The substrate is glued on the insulated beam pipe. The multiwire technique guarantees high inherent accuracy of the coils provided the beam pipe circumference is carefully matched to the width of the substrate. In order to achieve this, the diameter of the insulated pipe has to be accurate to \pm 1 mil. This is well below the tolerance of 3-4 mils with which the tubes can be specified, although experience shows that the tubes generally have a smaller diameter variation within single shipments. The tight tolerance on the insulated tube diameter is achieved by choosing the appropriate number of 1-mil-thick Kapton insulation layers.

Small plastic pins are precisely glued on the insulated beam pipe which fit into punched holes in the multiwire substrate. A long precise glueing fixture is needed for that purpose. The pins and holes ensure the correct angular alignment of the sextupole coil over the whole length. The estimated accuracy is 3 mrad. Precisely mounted plastic guides at the top and bottom of the beam pipe serve to align the coil inside the dipole. They fit into punched grooves in the collar. It is estimated that the sextupole coil is centered within the dipole coil with a precision of 4-5 mils. The angular alignment between sextupole and dipole field is accurate to about 5 mrad. (The specified tolerance is $0.5^{\circ}=8.8 \mathrm{mrad}$.) On the whole, it appears that the present design fulfills the requirements on mechanical accuracy. However, magnetic measurements are needed to determine the accuracy of centering and field alignment. Also, the multipole components of the sextupole coil have to be measured. Such measurements have not been made on the most recent design so far. They are indispensable to judge the quality of the coil, of course, and they will be made.

The coils are fixed on the beam pipe by glue joints and by an additional strong glass fiber wrapping. The latter should prevent motion of the conductors under the influence of the Lorentz forces. According to the experience with the HERA coils, a very high prestress $\left(800 \mathrm{~N} / \mathrm{cm}^{2}\right)$ is needed to ensure a secure clamping of the windings after cooldown. The prestress applied at BNL was not known to the panel.

Some concern was expressed that the outer Kapton wrapping of the coils might come loose in the accelerator. The panel felt that this wrapping could be omitted, if desired, by putting some more Kapton insulation underneath the epoxy-glass fiber compression wrapping.

Another concern expressed was that the coils contain a lot of plastic materials. Fortunately, it has been possible to modify the multiwire technique to use Kapton for the substrate and polyimid glue. All non-metallic materials are either Kapton or glass fiber; the glues are polyimid or epoxy. Consequently, the correction coils have therefore as good a radiation hardness as the main dipole coils.

The multiwire technique looks well advanced and adequate to produce the sextupole coils. The tooling developed at BNL is well suited to mount the coils on the beam tube and it appears 
to provide sufficient accuracy. As said above, however, this has to be demonstrated by magnetic measurement.

\section{Test Results}

First it must be noted that in the most recent specification, the sextupole to be compensated by the corrector at $6.6 \mathrm{~T}$ has been increased to 8 units from the former value of 4 units (reference: SSC-N-493). The present bore tube corrector is not adequate for this. One has to double the amount of superconductor in the coil. All tests to date refer to the "old specification" of 4 units.

Full-length correction coils of a previous design were built and tested but they displayed unacceptable training characteristics. Meanwhile, improvements have been made, including the Kapton substrate, G11 cores between the coil sections and alumina-filled epoxy between the part of the wires sticking out of the substrate. Only two short versions of the new design have been built and tested so far and no tests have been made of a full-length version in a full-length dipole.

The layout of the coils was based on the old specification of 4 units at $6.6 \mathrm{~T}$. For a 10-m coil with 10 windings per subcoil, this compensation requires a current of $12 \mathrm{~A}$. The superconductor has a 13-mil diameter, a copper to superconductor ratio of 2.25, and a filament diameter of $9 \mu \mathrm{m}$. The critical current at 6.6 $\mathrm{T}$ is about $35 \mathrm{~A}$. Quench tests were performed at 4.0,5.0, and 5.8 $\mathrm{T}$. The lowest quench current was above $45 \mathrm{~A}$ at $5.8 \mathrm{~T}$, but both coils showed training that repeated itself after the polarity was reversed. Unfortunately, no dipole was available to test the coils at the full field of $6.6 \mathrm{~T}$. Still, it appears likely that the coils will safely exceed the original operating current of $12 \mathrm{~A}$ at $6.6 \mathrm{~T}$ without quench. Efforts should be made to improve the training behavior. The HERA correction coils show little training. In particular, they do not retrain after changing the polarity or after a thermal cycle, but reach immediately the critical current of the superconductor. It is particularly important to demonstrate that $10-\mathrm{m}$-long coils can be built with satisfactory training properties.

\section{Heat Load from Synchrotron Radiation and Quenches due to Beam Loss}

The estimated heat load on a dipole is $2 \mathrm{~W}$ at nominal luminosity $\left(10^{33} \mathrm{~cm}^{-2} \mathrm{sec}^{-1}\right)$. With the new cooling scheme for the dipoles, the helium in the gap between beam pipe coil and dipole coil suffers negligible heating from this heat load. Assuming the most pessimistic values for the heat conductivity of Kapton it is estimated that the correction coil temperature might be $0.1 \mathrm{~K}$ higher than the helium temperature. This does not impact the operational thermal margin.

Another aspect is the heating of the correction coils due to beam losses. Hadron-induced showers deposit a higher energy density in the bore tube correctors than in the main dipole coil. Monte-Carlo studies have shown that in the HERA coils, the energy density is at least three times higher than in the main coils. If one wants to avoid that the beam pipe coils quench at lower beam loss rates than the main coils, one should operate the corrector coils at a much smaller fraction of the critical current. The design current of the HERA coils at maximum energy is about 30 percent of the critical current.

About the same number is obtained for the present SSC corrector if the coils had to compensate $a b_{2}$ of 4 units (operating current $12 \mathrm{~A}$, critical current about $35 \mathrm{~A}$ ). If a compensation of 8 units of $b_{2}$ is needed, as the present specification implies, the critical current should be doubled to keep the safety margin against beam-induced quenches. 


\section{Persistent Current Effects}

Superconducting wires inside a dipole field are "magnetized"; i.e., persistent eddy currents are induced inside the filaments. For a coil with sextupole symmetry, this leads to a decapole field. This has been verified experimentally for the HERA coils. At the injection energy the decapole generated by the sextupole correction coil is about as large as that from the main dipole and adds to it. The data are in quantitative agreement with calculations. M. A. Green has made a calculation of the decapole generated by the $S S C$ bore tube corrector. With the present design it will be about 0.7 units inside the 10-m-long coil (equivalent to 0.4 units distributed over $17 \mathrm{~m}$ ). If the amount of superconductor has to be doubled to enable a sextupole correction of 8 units at $6.6 \mathrm{~T}$, the persistent current decapole will also double. Since it adds to the decapole of the main dipole, it is a serious distortion, exceeding the specified limits for the net decapole error allowed. The decapole can be reduced by using finer filaments. If the bore tube corrector concept is further pursued, the filaments should be chosen as fine as possible, (This problem does not exist if the correction coils are placed in a separate package.)

\section{Schedules}

Bore tube correctors of 10-m length are currently being fabricated. DD0020 and further magnets will be equipped with such coils. Before installation in a dipole, the coils must be tested cryogenically to ensure that the superconductor is in order. All HERA coils have been tested prior to installation in a dipole field of $5.1 \mathrm{~T}$, and the vast majority have achieved the critical current of the conductor, but a few percent failed because of weak spots in the singlestrand superconductor. Staff at BNL foresee a test at a current of $300 \mathrm{~A}$ without external field. It must be verified that this test is sufficient to assure the desired performance of the coils in a $6.6 \mathrm{~T}$ field. If the bore tube corrector scheme is to be used, it is recommended to set up a test facility that allows to test the coils in a large dipole field over their whole length.

The time schedules of the bore tube correctors and the main dipoles are strongly linked, as these tubes are inserted into the dipole coils before collaring. The corrector must be considered a component of the dipole.

\section{Alternative Corrector Schemes}

A variety of corrector schemes for the SSC was presented by A. Chao. Sextupole and decapole correction is necessary both at low and high field, whereas the octupole correction is questionable. A solution which is considered as "excellent" from the accelerator point of view has sextupole bore tube correctors in each dipole and lumped sextupole and decapole correctors at the quadrupoles and in the center of a half cell. Omitting from this scheme the bore tube sextupole coils, Chao arrived at a scheme that he still considered as "good."

The design and construction of spool-piece correctors should be vigorously pursued, Such correctors are needed in any case at the main quadrupoles, e.g., for chromaticity correction. A knowledge of the layout, performance, and space requirements of such correctors is indispensable before a decision can be made how the correctors in SSC should look. So far no work has been done on "lumped correctors." 


\section{Impact of a Change of the Dipole Bore}

If the bore diameter of the dipole were increased from 4 to $5-\mathrm{cm}$, the bore tube correctors would be easier to fabricate, since the requirements on the mechanical accuracy are relieved like the ratio of the bore tube diameters. A dipole coil of $5 \mathrm{~cm}$ diameter will probably have smaller sextupole distortions at a radius of $1 \mathrm{~cm}$ than the present coil with $4-\mathrm{cm}$ diameter. This would allow a slight reduction of the amount of superconductor in the bore tube corrector. Increasing the bore tube radius leads to a significant reduction of the decapole field produced by the magnetization of the bore tube corrector wires (the decapole scales with the fifth power of the inverse coil radius). Also, the persistent current decapole generated by the main coil decreases. A careful study has to be made, but one would expect that the problems associated with the persistent current decapoles are significantly reduced.

Increasing the bore tube radius leads to a proportional increase in the superconductor needed to wind the coils. It is estimated that this has little impact on the production costs which are dominated by other factors and may even be lower for the larger tube diameter.

\section{Conclusions and Recommendations}

At present, the bore tube correctors are the only correction elements that have been worked on. Since they lie in the bore of the dipole, they are an integral part of the magnet design, and their development influences the magnet R\&D schedule. Alternative corrector schemes that are divorced from the dipole magnet design are possible and ought to be seriously considered. The final layout of the dipoles cannot be made before all magnetic elements in the cell are known. .

Bore tube correctors of 10-m length have to be tested inside long dipoles, and it has to be demonstrated that they operate with a high degree of reliability. A failure of an installed bore tube corrector is basically a failure of the (much more expensive) dipole. For this reason, a thorough performance test prior to installation is indispensable.

The panel feels that the techniques developed at BNL are adequate to produce reliable bore tube correction coils. However, the solution adopted for the HERA coils should be kept as an alternative option.

With the presently specified strength of sextupole correction at high field, the correction coils have to be made with a superconductor with a larger current capability than that of the wire now in use. It has to be demonstrated that the coils can stand the larger Lorentz forces safely.

The increase in persistent current decapole field should be reduced by going to finer filaments.

The bore tube design is advanced far enough that a reliable cost estimate can be made. Cost estimates are also needed for the alternative corrector schemes.

Several panel members expressed a preference for the lumped corrector scheme. However, before a decision could be made to adopt such a scheme, much work would have to be done. 


\section{APPENDIX A \\ Charge to the Collider Dipole Review Panel}

The Collider Dipole Review Panel (CDRP) shall carefully review, discuss, and report to me on the present status and future prospects of the laboratory-based SSC collider dipole R\&D development program and on the current best full-length magnet designs coming out of that program.

The purview of the panel shall be limited to assessment of the magnet performance relative to the SSC System Requirements. The panel is not commissioned to study or assess the appropriateness of the accelerator physics criteria. These criteria will be reviewed by a parallel accelerator physics panel devoted to this issue.

The panel then, should address the following general areas associated with the collider dipole design and comment on each:

- Design and Engineering Approach

- analytical tools and methods

- materials choice and characterization

- engineering codes and standards

- Mechanical Construction and Coil Support

- coil/collar/yoke/skin support system

- coil winding, curing, and end configuration

- coil cooling, insulation, and dimensions control

- Superconductor Materials and Cable Specification

- Cu:SC ratios, inner and outer coils

- SC critical current, magnetization, and time dependence

- cabling and mechanical properties control

- Bore Tube and Correction Coils

- correction coils technology

- correction coils geometry

- synchrotron radiation and beam impedance properties

- Cryostat, Vacuum, and Interconnections

- heat leak and cryogenic configuration

- mechanical support and position control

- vacuum vessels, bellows, and sealing techniques 
- Alignment, Field Quality, and Multipole Content

- vertical plane and aperture position control

- survey system and thermal behavior

- multipoles and warm/cold correlation

- Quality Control and Quality Assurance

- materials availability and quality control

- process simplicity and verification tests

- component marking, tracking and verification

- overall quality assurance plan

The panel is asked to assess the appropriateness and adequacy of the current R\&D design for each of these topics as well as the prospects for the successful industrialization of this baseline design into a production version that can continue to meet the system requirements. Of particular interest is the panel's assessment of the ability of the R\&D Managers to set proper and appropriate goals and to assess progress towards these goals. If the panel feels that there are other technical issues associated with the current collider dipole design that require comment, I will welcome these comments in the report as well.

I request that the panel prepare a written report containing its assessment of the topics noted above as well as its judgement of the quality and vigor of the present R\&D program. The panel is free and encouraged to make any other general recommendations to me as it sees fit. I will also seek an in-person meeting with the members of the panel after having digested the preliminary written report.

The preliminary written report of the panel is due April 28, 1989. The final written report is due June 1, 1989.

Roy F. Schwitters

March 21, 1989 


\section{APPENDIX B \\ Collider Dipole Review Panel Members}

March 20, 1989
Address

CERN SPS Division CH-1211 Geneve 23 Switzerland

1610 Goodridge Dr. McLean, VA 22102

U.S. DOE - ER 90

Washington, DC 20545

One Cyclotron Rd. MS 80-225

Berkeley, CA 94720

Engr. Mechanics Dept. 256 Engr. Mech. Bldg GM Technical Center Warren, MI 48090

4802 Research Forest Dr,

Bldg. 2

The Woodlands, TX 77381

Hartwig Kaiser DESY

Robert Kephart Fermilab

Tom Kirk

(co-chairman)

Ted Kozman

Peter J. Limon
SSC Lab

LBL

SSC Lab
Notkestrasse 85

D-2000 Hamburg-52

Federal Republic of Germany

MS 223

P.O. Box 500

Batavia, IL 60510

One Cyclotron Rd.

MS 90-4040

Berkeley, CA 94720

One Cyclotron Rd.

MS 90-2148

Berkeley, CA 94720

One Cyclotron Rd.

MS 90-4040

Berkeley, CA 94720
Phone/Fax (in italics)

41-22-835392

41-22-836555

703-448-6405

703-821-1037

$301-353 \pi 5490$

301-353-5079

415-486-5868

313-986-2027

313-986-1532

713-363-7925

713-292-0156

49-40-8998-0

49-40-8998-3282

312-840-3135

312-840-4343

415-486-6309

415-486-6119

415-486-5275

415-486-6119

415-486-6343

415-486-6796 


\begin{tabular}{|c|c|c|c|}
\hline Dick Lundy & Fermilab & $\begin{array}{l}\text { MS } 105 \\
\text { P.O. Box } 500 \\
\text { Batavia, IL } 60510\end{array}$ & $\begin{array}{l}312-840-3211 \\
312-840-2939\end{array}$ \\
\hline Harvey Lynch & SLAC & $\begin{array}{l}\text { P.O. Box } 4349 \\
\text { Bin } 96 \\
\text { Stanford, CA } 94309\end{array}$ & $\begin{array}{l}415-926-3691 \\
415-926-3626\end{array}$ \\
\hline Paul Mantsch & Fermilab & $\begin{array}{l}\text { MS } 316 \\
\text { P.O. Box } 500 \\
\text { Batavia, IL } 60510\end{array}$ & $\begin{array}{l}312-840-4940 \\
312-840-3756\end{array}$ \\
\hline Michael McAshan & SSC Lab & $\begin{array}{l}\text { One Cyclotron Rd. } \\
\text { MS 90-4040 } \\
\text { Berkeley, CA } 94720\end{array}$ & $\begin{array}{l}415-486-6932 \\
415-486-6796\end{array}$ \\
\hline Romeo Perin & CERN & $\begin{array}{l}\text { SPS Division } \\
\text { CH-1211 Geneve } 23 \\
\text { Switzerland }\end{array}$ & $\begin{array}{l}41-22-767-3285 \\
41-22-767-2850\end{array}$ \\
\hline Paul Reardon & SAIC & $\begin{array}{l}227 \text { Wall St. } \\
\text { Research Park } \\
\text { Princeton, NJ } 08540\end{array}$ & $\begin{array}{l}609-921-9030 \\
609-921-3576\end{array}$ \\
\hline John Rees & SLAC & $\begin{array}{l}\text { P.O. Box } 4349 \\
\text { Bin } 07 \\
\text { Stanford, CA } 94309\end{array}$ & $\begin{array}{l}415-926-2504 \\
415-926-3626\end{array}$ \\
\hline E. Parke Rohrer & $\mathrm{BNL}$ & $\begin{array}{l}\text { Bldg. } 902 \\
\text { Upton, NY } 11973\end{array}$ & $\begin{array}{l}516-282-7512 \\
516-282-2170\end{array}$ \\
\hline Ron Scanlan & LBL & $\begin{array}{l}\text { One Cyclotron Rd. } \\
\text { MS 46-161 } \\
\text { Berkeley, CA } 94720\end{array}$ & $\begin{array}{l}415-486-7241 \\
415-486-4873\end{array}$ \\
\hline Peter Schmüser & DESY & $\begin{array}{l}\text { Notkestrasse } 85 \\
\text { D-2000 Hamburg-52 } \\
\text { Federal Republic of Germany }\end{array}$ & $\begin{array}{l}49-40-8998-0 \\
49-40-8998-3282\end{array}$ \\
\hline Rae Stiening & SSC Lab & $\begin{array}{l}\text { One Cyclotron Rd. } \\
\text { MS 90-4040 } \\
\text { Berkeley, CA } 94720\end{array}$ & $\begin{array}{l}415-486-6309 \\
415-486-6119\end{array}$ \\
\hline Alvin Tollestrup & Fermilab & $\begin{array}{l}\text { MS } 223 \\
\text { P.O. Box } 500 \\
\text { Batavia, IL } 60510\end{array}$ & $\begin{array}{l}312-840-4331 \\
312-840-4343\end{array}$ \\
\hline $\begin{array}{l}\text { Gus Voss } \\
\text { (co-chairman) }\end{array}$ & $\begin{array}{l}\text { SLAC } \\
\text { (on-leave from DESY) }\end{array}$ & $\begin{array}{l}\text { P.O. Box } 4349 \\
\text { Bin } 26 \\
\text { Stanford, CA } 94309\end{array}$ & $\begin{array}{l}415-926-2364 \\
415-926-3626\end{array}$ \\
\hline
\end{tabular}

\section{Observer}


Helen Edwards $\quad$ SSC Laboratory

2550 Beckleymeade Ave., Ste. 260

Dallas, TX 75237
214-709-9921

214-298-5451 


\section{APPENDIXC \\ Final Collider Dipole Review Panel Agenda \\ April 17-21, 1989}

Bldg. 90, 4th Floor, Cockpit

LBL Berkeley, CA

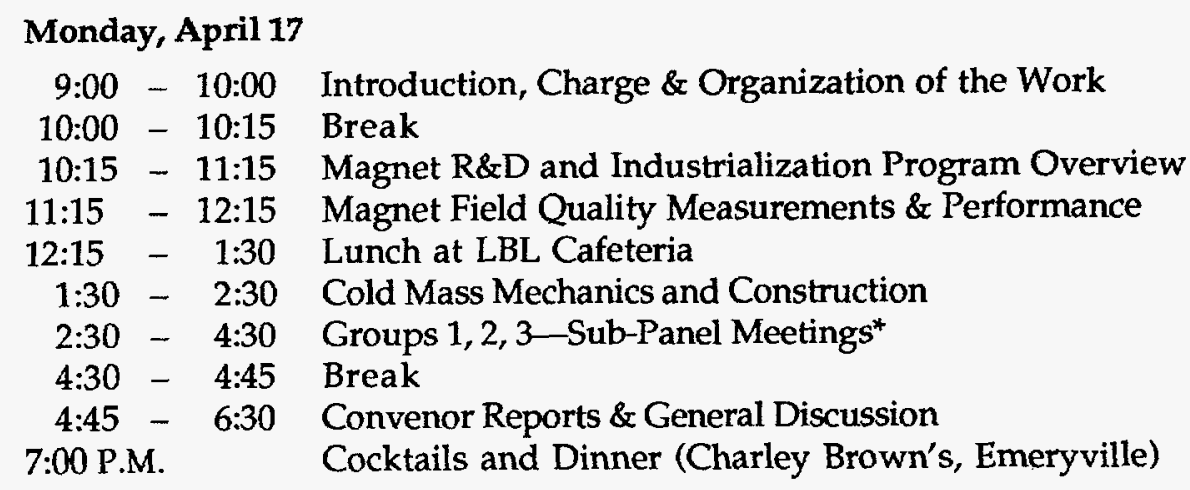

G. Voss

T. Kirk

P. Wanderer

P. Mantsch

\section{Tuesday, April 18}

$\begin{array}{rll}\text { 8:00 } & -9: 00 & \text { Superconductor Status } \\ 9: 00-10: 00 & \text { Coil Insulation, Winding and Curing } \\ 10: 00-10: 15 & \text { Break } \\ 10: 15-11: 15 & \text { Bore Tube Correctors \& Coil Cooling } \\ 11: 15-12: 45 & \text { Groups 1, 2, 3-Sub-Panel Meetings* } \\ 12: 45-1: 45 & \text { Lunch at LBL Cafeteria } \\ 1: 45-3: 45 & \text { Groups 1,3, 4-Sub-Panel Meetings } \\ 3: 45-4: 00 & \text { Break } \\ 4: 00-5: 30 & \text { Convenor Reports \& General Discussion }\end{array}$

R. Scanlan

E. Kelly

E. Willen

Wednesday, April 19

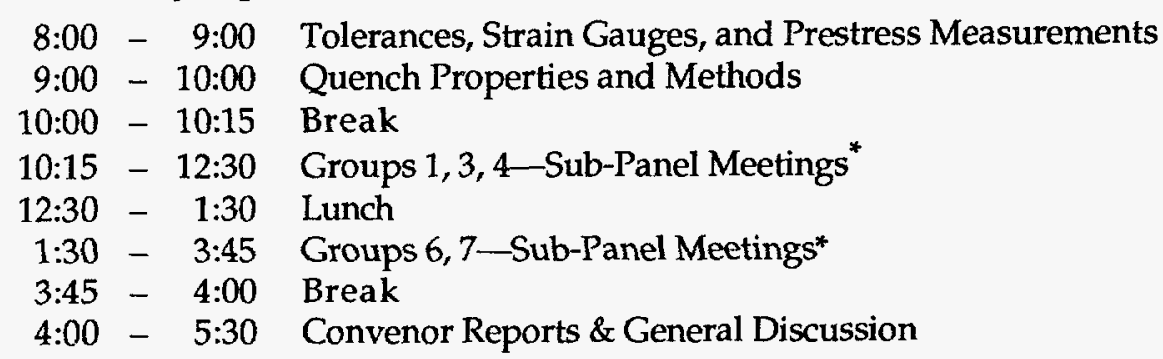

C. Goodzeit

P. Limon

Thursday, April 20

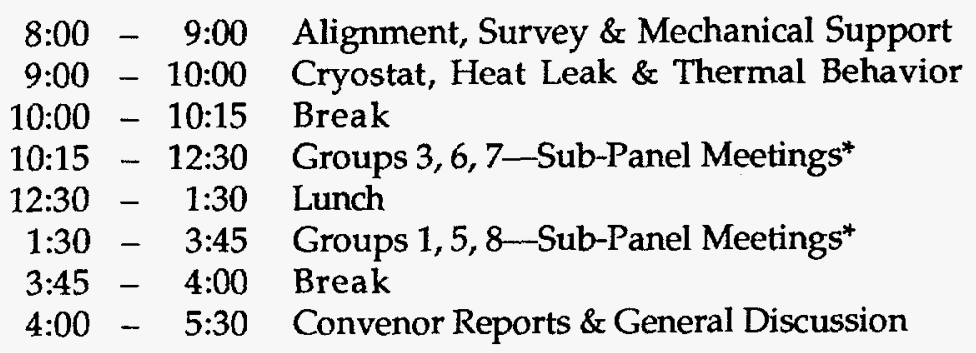

T. Nicol, J. Carson

R. Niemann

Friday, April 21

8:00 - 12:30 Convenor Reports \& General Discussion

12:30 - 1:30 Adjourn 
${ }^{*}$ Groups that met each day are given by the list on the page 2 . 


\section{APPENDIX C - Page 2 \\ Final Discussion Topics and Convenors}

The discussion topics noted (and numbered) below have been identified in order to cover fully the important topics that need to be addressed by the panel. On each day, the whole panel will distribute themselves among the three active discussion topics to be pursued in parallel on that day. The two convenors will guide the discussion, report on topical results to the plenary meetings at the end of the day, and draft the report sections on the topics on which they report. Each topic will receive a list of key sub-topics to be addressed by the time of the panel's start on April 17. Additional contributions to the topical baskets can be made by panel members through the panel co-chairmen.

\begin{tabular}{cl}
$\begin{array}{c}\text { Group No. } \\
1\end{array}$ & \multicolumn{1}{c}{ Topic } \\
2 & $\begin{array}{l}\text { R\&D Program Management } \\
\text { and Industrialization } \\
\text { Magnetic Field Measurements }\end{array}$ \\
3 & Cold Mass Mechanics \\
4 & Superconductor, Wire \& Cable \\
5 & Cryogenics \\
6 & Quench Protection \\
7 & Correction Coils
\end{tabular}

(at large)

\section{Convenors}

Paul Reardon Tom Bush

Alvin Tollestrup Klaus Halbach

Hartwig Kaiser Romeo Perin Russ Huson

Dick Lundy Fred Asner

Mike McAshan Ted Kozman

Bob Kephart Harvey Lynch

Peter Schmüser John Rees

W. Fietz Larry Howell 